International Journal of Advanced Academic Research | Sciences, Technology and Engineering | ISSN: 2488-9849 Vol. 6, Issue 6 (June, 2020) |www.ijaar.org

Journal DOI: 10.46654/ij.24889849 | Article DOI: 10.46654/ij.24889849.e664

\title{
ISOLATION AND IDENTIFICATION OF KERATINOLYTIC BACILLUS SPECIES FROM CHICKEN FEATHER DUMP SITES
}

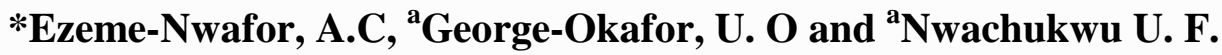 \\ *Corresponding author: Department of Microbiology, Faculty of Natural Sciences, Caritas \\ University, Amorji-Nike Enugu, Nigeria. \\ Email: amyomajesus@yahoo.com. \\ ${ }^{\mathrm{a} D e p a r t m e n t ~ o f ~ A p p l i e d ~ M i c r o b i o l o g y ~ a n d ~ B r e w i n g, ~ F a c u l t y ~ o f ~ A p p l i e d ~ N a t u r a l ~ S c i e n c e s, ~}$ \\ Enugu State University of Science and Technology. Enugu, Nigeria.
}

\begin{abstract}
This study investigated the isolation and identification of keratinolytic Bacillus species isolated from chicken feather dump sites. From the study, a total of twenty-one (21) Bacillus species were isolated from different feather dumping sites by culture dependent method and identified based on their morphological and biochemical characteristics. Out of the 21 isolates screened, 12 had clear zones of inhibition on feather meal agar indicating keratinase production with two isolates having the highest zone of inhibition of 20mm (A11) and 24mm (A5) in diameter each on feather meal agar was selected and identified. The two Bacillus species were characterized morphologically and biochemically based on Bergey's manual of determinative bacteriology as well as molecular characterization by sequencing $16 S$ rRNA gene. The two isolates were identified as Bacillus safensis LRF3X (A5) and Bacillus cereus35 (A11). The percentage degradation of feathers by the isolates was also studied with Bacillus safensis LRF3X yielding $100 \%$ degradation on the seventh day (168hr). The results obtained from this study showed that keratinase is produced from Bacillus safensis LRF3X and can be useful in degradation of keratinous wastes (feathers), recycling to poultry feeds and also find applications in pharmaceutical, leather, cosmetics industries etc.
\end{abstract}

Keywords: keratinase, Bacillus safensis, Bacillus cereus 35, feathers, isolation. 


\section{Introduction}

Keratinase is an important enzyme of protease family which can be involved in cleaning the environment by degrading keratins (Agrahari and Wadhwa, 2010). This Keratinases belong to serine or metallo proteases (Gupta and Ramnani, 2006). The Common proteolytic enzymes such as pepsin, trypsin and papain cannot breakdown keratins because of their rigid structure. Keratinous substances are found in feathers skin, hair, horns, hooves, cloves, nails, beaks, reptilian osteoderm, etc. (McKittrick et al., 2012). Keratin materials make animals more resistant against both abiotic stress and biotic attacks. Since microbial degradation of keratin is not widespread in nature, keratin can serve as a good defense against microbial attack. Keratin can be said to be recalcitrant. Unfortunately, these keratinous substances are not easily degradable and so they are often dumped or burnt thus, creating potential environmental pollutions (Dipak et al., 2015). Feathers had been the most common keratinous materials found in the environment as a result of the increasing demand of chicken. Poultry processing houses have been accumulating lots of feathers worldwide. These keratinous wastes could have great potential as a source of protein and amino acids for animal feed. However, the current processes using heat and chemical treatments to obtain feather meal are unfriendly to environment and also destroy amino acids, giving rise to a product with poor digestibility and low nutrient quality (Mabrouk, 2008; Sangali and Brandelli, 2000).

Fortunately, keratinases from micro-organisms could solve these problems effectively when they are used to process these wastes to products. Many microorganisms such as Bacillus spp., Burkholdreia, Chryseobacterium, Pseudomonas, Micrococcus spp. and some fungi etc. can produce keratinase enzyme (Anbu et al., 2004; Riffel et al., 2003). This enzyme is proteolytic in nature. It is serine protease. The Use of keratinolytic microorganisms or keratinases can be a good alternative for recycling these keratinous wastes into cheap and supplementary protein for poultry feeds, organic fertilizers, dehairing in leather industry and in clearing obstructions in sewages during waste water treatment (Mohamed et al., 2014). In this study, isolation and identification of keratinolytic Bacillus species from feather dump sites was done.

\section{Materials and Methods}

\section{Sample Collection}

Soil samples of about 2-6cm deep were collected with sterile container from different feather dump sites in Enugu State, Nigeria and taken to the Laboratory.

\section{Isolation of Bacillus species}

A tenfold serial dilution of soil samples was done and cultured using the pour plate method into nutrient media plates. The plates were incubated at $37^{\circ} \mathrm{C}$ overnight. After incubation, pure isolates were characterized and identified. 


\section{Identification of isolates}

Pure isolates were identified based on their cultural, morphological and biochemical characteristics based on the taxonomic scheme of Barrow and Feltham (1993) and reference to Holt et al. (1992). These include gram stain, spore staining, motility test, catalase test, oxidase, coagulase, urease, indole test, hydrogen sulphide test, nitrate reduction, methyl red, VogesProskauer, oxidative/fermentative test and utilization of sugar.

\section{Processing of the Keratinolytic Substrates}

Raw Feathers were used as the substrates. The raw feathers were washed extensively with water. The feather was oven dried at $70^{\circ} \mathrm{C}$ for $48 \mathrm{~h}$. The dried feathers were milled using a manual grinder to fine powder which served as a sole source of carbon and nitrogen.

\section{Isolation of Keratinase producing microorganisms}

One gram of each soil sample was transferred into $9 \mathrm{ml}$ sterile distilled water. The sample was serially diluted. Screening of the isolates was done by streaking cultures of the isolates on basal feather meal agar plates using the methods of Agrahari and Wadhwa (2010) with a slight modification ( $\mathrm{g} / \mathrm{l}: \mathrm{NH}_{4} \mathrm{Cl} 0.5, \mathrm{NaCl} 0.5, \mathrm{~K}_{2} \mathrm{HPO}_{4} 0.3, \mathrm{KH}_{2} \mathrm{PO}_{4} 0.3, \mathrm{MgSO}_{4} 0.1$, yeast extract 0.1 , feather powder 10 , agar $12, \mathrm{pH} 7.5$ ). The cultures were incubated for $2-5$ days for colony formation. Keratin degradation was indicated by the formation of clear zone of hydrolysis around the colonies. Strains which showed maximum zones of clearance were selected.

\section{Determination of Degree of Degradation (DD) of Chicken Feather by Keratinase Producers}

Keratinous wastes (chicken feathers $1 \% \mathrm{w} / \mathrm{v}$ ) were added to the feather meal medium ( $\mathrm{g} / \mathrm{l}$ $: \mathrm{NH}_{4} \mathrm{Cl} 0.5, \mathrm{NaCl} 0.5, \mathrm{~K}_{2} \mathrm{HPO}_{4} 0.3, \mathrm{KH}_{2} \mathrm{PO}_{4} 0.3, \mathrm{MgSO}_{4} 0.1$, yeast extract $0.1, \mathrm{pH} 7.5$ ) as a sole source of carbon and nitrogen. After inoculation of isolates in different flasks, the flasks were incubated at room temperature in a rotary shaker at $160 \mathrm{rpm}$ for 2 -7days. The percentage degradation of keratinous waste was then calculated (Harison and Singh, 2014). The residual feather was washed, dried and weighed to calculate DD by using following formular.

$$
\mathrm{DD}(\%)=\frac{(\mathrm{TF}-\mathrm{RF}) \times 100}{\mathrm{TF}}
$$

Where, TF is total feather and RF is residual feather.

\section{Identification of keratinase producing bacteria}

Morphological and a range of biochemical tests were performed in order to identify the isolate. The isolate was identified based on morphological, biochemical characteristics as described in the Bergey's manual of systematic bacteriology and by 16S rRNA gene sequencing using MEGA6 (Tamura et al., 2013). 


\section{Keratinase Enzyme production}

The keratinase enzyme production was carried out in the basal medium by using shaker incubator. The composition of the medium was $(\mathrm{g} / \mathrm{l})$ : feathers $(10 \mathrm{~g}), \mathrm{NH} 4 \mathrm{Cl} 0.5, \mathrm{NaCl} 0.5$, K2HPO4 0.3, KH2PO4 0.3, MgSo4 0.1, yeast extract 0.1, (Rajesh et al. 2014). Fermentation was carried out with $1 \%(\mathrm{v} / \mathrm{v})$ inoculum at $30{ }^{\circ} \mathrm{C}$ for 7 days at $150 \mathrm{rpm}$. After incubation, the broth was centrifuged and the supernatant was used to assay for keratinase activity.

\section{Determination of keratinase activity}

One milliliter of $1 \%$ powdered feather was mixed with $0.2 \mathrm{ml}$ of phosphate buffer $(\mathrm{pH} 8.0)$ and $0.5 \mathrm{ml}$ of enzyme solution in test tubes. The solution was incubated for $30 \mathrm{~min}$ at $30^{\circ} \mathrm{C}$. After incubation, the undegraded feather powder precipitate was removed by centrifugation at 10000 rpm for $10 \mathrm{~min}$. One milliliter $(1 \mathrm{ml})$ of the supernatant was mixed with $5 \mathrm{ml}$ of $4.2 \%$ sodium carbonate $\left(\mathrm{Na}_{2} \mathrm{CO}_{3}\right)$ and $0.5 \mathrm{ml}$ of Folin Ciocalteau phenol reagent. The reaction mixture was precipitated by standing in ice for $15 \mathrm{~min}$ and insoluble precipitate was removed by centrifugation at $10000 \mathrm{rpm}$ for $10 \mathrm{~min}$. Absorbance of the supernatant was read at $660 \mathrm{~nm}$. A control assay, without the enzyme in the reaction mixture was done and used as the blank in all spectrophotometric measurements. All assays were done in duplicate. One unit of keratinase activity was defined as the amount of enzyme that released one microgram of tyrosine per min under standard assay conditions (Sreenivasa et al., 2013).

\section{Results and Discussion}

Isolation, Screening and Identification of Keratinase Producing Bacillus species.

A total of 21 different Bacillus isolates were isolated. Out of the 21 isolates screened, 12 Bacillus species showed hydrolysis of keratin as seen in table 1. Bacillus cereus had the highest percentage occurrence of $41.67 \%$ while Bacillus safensis had the lowest percentage occurrence of $8.33 \%$. The percentage degradation of the feather was also calculated as shown in table 2 . Isolate A5 and A11 which had the best hydrolysis as seen in fig. 1 and 2 were selected and identified as Bacillus safensis LRF3X and Bacillus cereus35 (fig. 3 and 4) using molecular methods. There are previous reports on the isolation of keratinase producing strains of $B$. subtilis, B. licheniformis, B. pumilus, B. cereus, B. halodurans and B. weihenstephanensis, (Agrahari, 2013; Tiwary and Gupta, 2013; Tork et al., 2013; Lateef et al., 2010). Agbaje et al. (2015) was the first to report Bacillus safensis as a keratinase producer and till date, there had been scarce report on this isolate's ability to degrade feathers.

\section{Determination of Degree of Degradation of Chicken Feather by Keratinase Producers}

Among the 12 isolates, A5 isolate demonstrated highest feather degrading activity (100\%) followed by isolate A11 (85\%) after 7 days incubation where degradation of all feather barbules and almost all feather rachises were observed (Table 2). This result is in line with reports of Agbaje et al., (2015). There are reports of complete or partial degradation of chicken feathers by bacteria in the range of 4 to 10 days (Agrahari, 2013; Tiwary and Gupta, 2013; Tork et al., 2013; Lateef et al., 2010). 
Determination of Keratinase activity

The keratinase enzyme activities of Bacillus safensis LRF3X and Bacillus cereus35 were also studied. From the study, B. safensis LRF3X gave $38.33 \mathrm{U} / \mathrm{ml}$ enzyme activity while $B$. cereus 35 gave $32.21 \mathrm{U} / \mathrm{ml}$ activity as shown in table 3 .

Table 1: Table showing measurements of hydrolysis on Feather Meal Agar.

\begin{tabular}{llc}
\hline s/n & Isolates & $\begin{array}{l}\text { Clear zone of } \\
\text { hydrolysis } \\
\text { (mm) }\end{array}$ \\
\hline A1 & Bacillus licheniformis & 12 \\
A2 & Bacillus cereus & 18 \\
A3 & Bacillus subtilis & 10 \\
A4 & Bacillus cereus & 16 \\
A5 & Bacillus safensis & 24 \\
A6 & Bacillus licheniformis & 8 \\
A7 & Bacillus subtilis & 12 \\
A8 & Bacillus cereus & 16 \\
A9 & Bacillus cereus & 19 \\
A10 & Bacillus licheniformis & 10 \\
A11 & Bacillus cereus & 20 \\
A12 & Bacillus subtilis & 10 \\
\hline
\end{tabular}

Table 2: Percentage degradation of keratin by isolates.

\begin{tabular}{|c|c|c|c|c|}
\hline $\mathrm{s} / \mathrm{n}$ & Isolates & $\begin{array}{l}\text { Total } \\
\text { feather }(\mathrm{g})\end{array}$ & $\begin{array}{l}\text { Residual feather } \\
(\mathrm{g})\end{array}$ & $\%$ degradation \\
\hline A1 & Bacillus licheniformis & 1.0 & 0.4 & 60 \\
\hline A 2 & Bacillus cereus & 1.0 & 0.2 & 80 \\
\hline A3 & Bacillus subtilis & 1.0 & 0.5 & 50 \\
\hline A4 & Bacillus cereus & 1.0 & 0.4 & 60 \\
\hline A5 & Bacillus safensis & 1.0 & 0.0 & 100 \\
\hline A6 & Bacillus licheniformis & 1.0 & 0.6 & 40 \\
\hline A7 & Bacillus subtilis & 1.0 & 0.5 & 50 \\
\hline A8 & Bacillus cereus & 1.0 & 0.3 & 70 \\
\hline A9 & Bacillus cereus & 1.0 & 0.2 & 80 \\
\hline A10 & Bacillus licheniformis & 1.0 & 0.5 & 50 \\
\hline A11 & Bacillus cereus & 1.0 & 0.15 & 85 \\
\hline A12 & Bacillus subtilis & 1.0 & 0.6 & 40 \\
\hline
\end{tabular}

Table 3: Table showing keratinase activity of isolates

\begin{tabular}{ll}
\hline \multicolumn{1}{c}{ Isolate } & Keratinase activity (U/ml) \\
\hline Bacillus cereus 35 & $\mathbf{3 2 . 2 1}$ \\
Bacillus safensis LRF3X & $\mathbf{3 8 . 3 3}$ \\
& \\
\hline
\end{tabular}




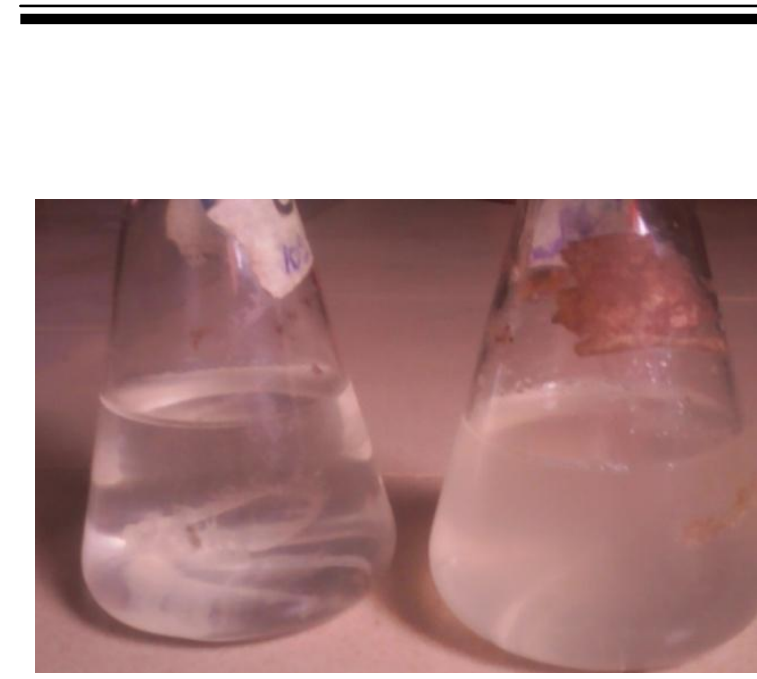

A

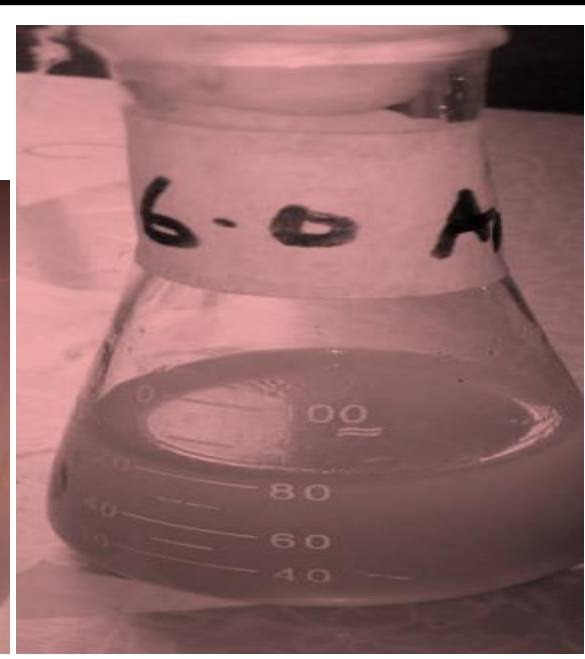

$\mathrm{C}$

Fig.1: A: Control, B: Image showing complete degradation of feathers by B. safensis LRF3X(A5) in feather meal broth. C: Image showing almost a complete degradation of feathers by $B$. cereus 35(A11) in feather meal broth.

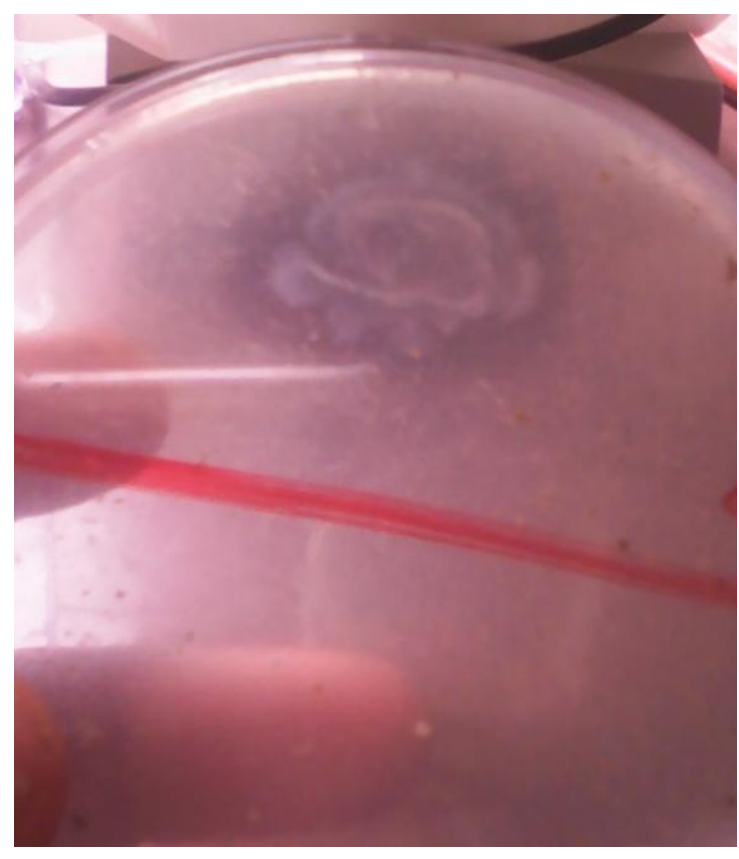

A

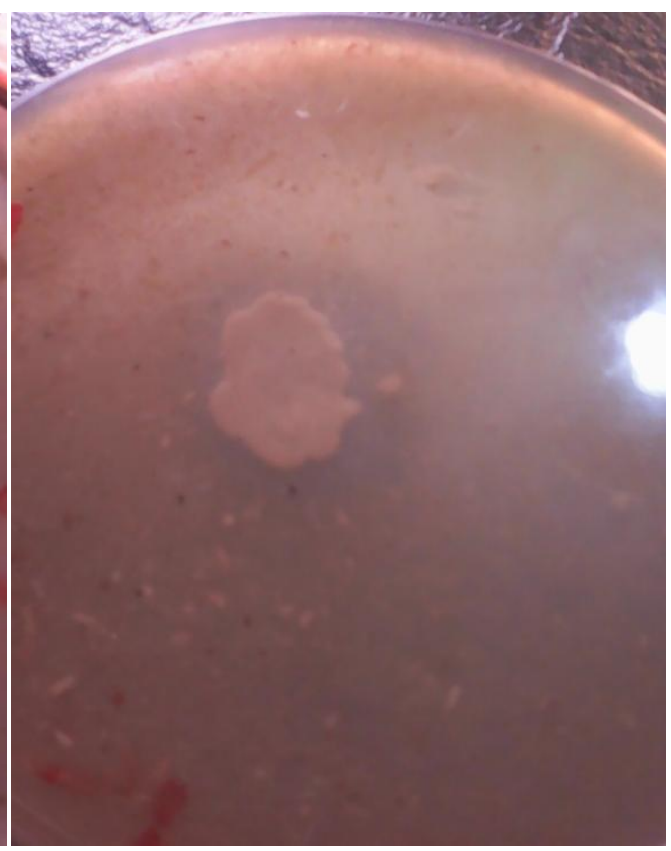

B

Figure 2: A: Image showing Bacillus safensis LRF3X(A5) hydrolysis on Feather meal agar, B: Image showing Bacillus cereus 35(A11) hydrolysis on Feather meal agar 
Image showing Genomic DNA

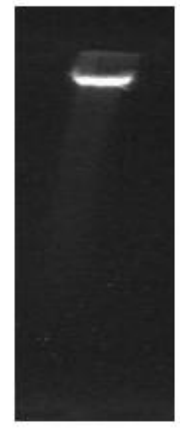

16SrRNA gene amplification results

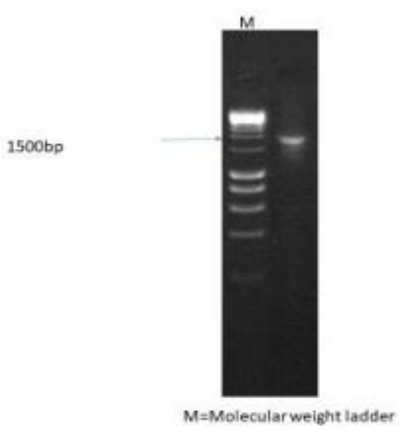

Fig. 3a: Image showing genomic DNA of Bacillus safensis LRF3X.
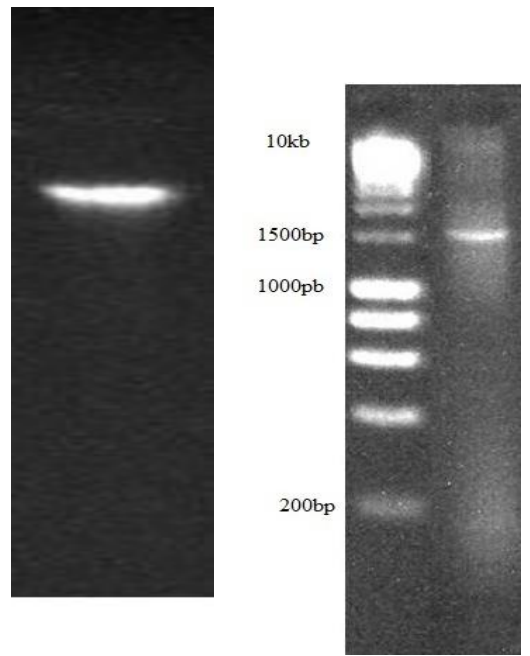

Fig. 3b: Image showing genomic DNA of Bacillus cereus 35. 


\section{Conclusion}

The results obtained from this study indicates that these isolates or their purified enzymes could be useful in the biotechnological management of chicken feathers through efficient biodegradation, recycling to poultry feeds and could also find applications in leather, pharmaceutical and cosmetics industries. Further studies on the purification of keratinase enzyme from these isolates are therefore recommended for effective management of these chicken feathers. 


\section{REFERENCES}

Agbaje, L., Isiaka, A., Adelerea, B. and Evariste, B. G. (2015). Bacillus safensis LAU 13: a new source of keratinase and its multi-functional biocatalytic applications. Biotechnology \& Biotechnological Equipment. 29(1): 5463.

Agrahari, S. (2013). Production of extracellular keratinase enzymes from Bacillus pumilis SN3 isolated from soil sample of Ghazipur poultry waste site. Int J Sustainable Dev Green Econ. 2:26.

Agrahari, S. and Wadhwa, N. (2010). Degradation of chicken feather a poultry waste product by keratinolytic bacteria isolated from dumping site at Ghazipur poultry processing plant, Int. J. Poult. Sci., 9(5), 482-489.

Allpress, J.D., Mountain, G. and Gowland, P.C. (2002). Production, purification and characterization of an extracellular keratinase from Lysobacter NCIMB 9497. Lett. Applied Microbiol., 34: 337-342.

Anbu, P., Gopinath, S.C.B., Hilda, A., Lakshmipriya, T. and Annadurai, G. (2005). Purification of keratinase from poultry farm isolate Scopulariopsis brevicaulis and statistical optimization of enzyme activity. Enzym Microb Technol. 36:639647.

Brandelli, A. and Riffel, A. (2005) Production of an extracellular keratinase from Chryseobacterium sp. growing on raw feathers, Electr. J. Biotechnol., 8(1), 35-42.

Chaturvedi, V., Bhange, K., Bhatt, R. and Verma, P. (2014). Production of keratinases using chicken feathers as substrate by a novel multifunctional strain of Pseudomonas stutzeri and its dehairing application. Biocatalysis Agric Biotechnol. 3:176174.

Cheng, S.W., Hu, H.M. and Shen, S.W. (1995). Production and characterization of keratinase of a feather degrading Bacillus licheniformis PWD-1. Biosci. Biotechnol. Biochem., 59: 2239-2243.

Dipak, K. S., Suman, K.H. and Arpan, D.K. (2015). Keratinase production by $B$. weihenstephanensis PKD5 in solid-state fermentation and its milk clotting potential. Indian J. of Biotech. 14:200-207.

Gupta, R. and Ramnani, P. (2006). Microbial keratinases and their prospective applications: an overview, Appl. Microbiol. Biotechnol., 70: 21-33.

Harison, M. and Sandeep, S. (2014). Degradation of keratinous waste products by keratinolytic bacteria isolated from soil. International Journal of Engineering and Computer Science. 3(8):7588-7595.

Jeevana, P. Lakshmi, C.H., Kumari, M. Chitturi, and. Lakshmi, V. V. (2013). Efficient Degradation of Feather by Keratinase Producing Bacillus sp. International Journal of Microbiology. Volume 7 http://dx.doi.org/10.1155/20

Kanchana, R. and Mesta, D. (2013). Native feather degradation by a keratinophilic fungus. Int J ChemTech Res. 5 (6):29472954.

Kainoor, P.S. and Naik, G.R. (2010). Production and characterization of feather degrading keratinase from Bacillus sp. JB 99, Indian J. Biotechnol.,9, 384-390 
Lateef, A., Oloke, J.K., Gueguim, E.B., Sobowale, B.O., Ajao, S.O. and Bello, B.Y. (2010). Keratinolytic activities of a new feather degrading isolate of Bacillus cereus LAU08 isolated from Nigerian soil. International Journal of Biodeterioration and Biodegradation. 64:162-165.

Lin, H.H. and Yin, L.J., (2010). Feather meal and rice husk enhanced keratinase production by Bacillus licheniformis YJ4 and characterization of produced keratinases, J. Mar. Sci. Technol., 18(3), 458-465.

Mohamed, A.H., Bakry, M.H., Amro, A.A. and Serour, A.E. (2015). Production and characterization of keratinolytic protease from new wool-degrading Bacillus species isolated from Egyptian ecosystem. BioMed Research International. 14. Article ID: 175012.

Mabrouk, M.E.M. (2008). Feather degradation by a new keratinolytic Streptomyces sp. MS-2. World J Microbiol Biotechnol. 24, 2331-2338.

McKittrick, J., Chen, P.Y., Bodde, S.G., Yang, W., Novitskaya, E.E. and Meyers, M.A. (2012). The structure, functions, and mechanical properties of keratin. JOM. 64:449-468.

Revathi, K., Shaifali, S., Mohd, A.K. and Suneetha, V. (2013). A potential strain of keratinolytic bacteria VIT RSAS2 from Katpadi and its pharmacological benefits. Int $J$ Pharm Sci Rev. 20:8992.

Riffel, A., Ortolan, S. and Brandelli, A. (2003). Dehairing activity of extracellular proteases produced by keratinolytic bacteria. J. Chem. Technol. Biotechnol., 78: 855-859.

Santos, R.M.D.B., Firmino, A.A., Desa, C. and Felix, C.R.(1996). Keratinolytic activity of Aspergillus fumigates. World J.Microbiol, 33: 364-370.

Saibabu, F.N. and Sunil, S.M. (2013). Isolation, partial purification and characterization of keratinase from Bacillus megaterium. International Research Journal of Biological Sciences. 2(2):13-20.

Sandeep, S., Harison, M.G., Ebenezer, J., Rubina, L. and Ramteke, P.W. (2017). Optimization of fermentative production of keratinase by $B$. subtilis SI in submerged state fermentation using feather wastes. Int. curr. Microbial.App. Sci. 6(2):1499-1510.

Sangali, S. and Brandelli, A. (2000). Feather keratin hydrolysis by a Vibrio sp. strain kri. J. Applied Microbiol., 89: 735-743.

Sahoo, D.K., Das, A., Thatoi, H., Mondal, K.C. and Mohapatra, P.K.D. (2012). Keratinase production and biodegradation of whole chicken feather keratin by a newly isolated bacterium under submerged fermentation. Appl Biochem Biotechnol. 167:10401051.

Sivakumar T, Shankar T, Vijayabaskar P. and Ramasubramaman, V. (2012). Optimization for keratinase enzymes production using Bacillus thuringiensis. Academic Journal of Plant of Sciences. 5(3):102-109.

Suntornsuk, W., Tongjun, J., Onnim, P., Oyama, H., Ratanakanokchai, K., Kusamran,T. and Oda, K. (2004). Purification and characterisation of keratinase from a thermotolerant feather-degrading bacterium, World J. Microbiol.

Biotechnol.,21, 1111-1117. 
Suntornsuk, W. and Suntornsuk, L. (2003). Feather degradation by Bacillus sp. FK 46 in submerged cultivation. Bioresour. Technol., 86: 239-243.

Sreenivasa, N., Gireesh, B.K. and Vidyasagar, G.M. (2013). Purification and characterization of keratinase from hair-degrading Streptomyces albus. International Journal of Bioassays. 2(3): 559-604.

Tamura, K., Strecher, G., Peterson, D., Filipska, A. and Kumar, S. (2013). MEGA6: Molecular evolutionary genetics analysis version 6.0. Molecular Biology Evolution. 30: 2725-2729.

Tiwary, E. and Gupta, R. (2013). Rapid conversion of chicken feather to feather meal using dimeric keratinase from Bacillus licheniformis ER-15. J Bioprocess Biotechnol. 2:123. doi: 10.4172/2155-9821.1000123. [30].

Tork, S.E., Shahein, Y.E., El-Hakim, A.E., Abdel-Aty, A.M. and Aly, M.M. (2013). Production and characterization of thermostable metallo-keratinase from newly isolated Bacillus subtilis NRC 3. Int J Biol Macromol. 55:169175.

Venkata, S., Francois, N.N. and Sunil, S.M. (2013). Isolation, partial purification and characterization of keratinase from Bacillus megaterium. International Research Journal of Biological Sciences. 2(2):13-20.

Wang, J.J. and Shih, J.C.H. (1999). "Fermentation production of keratinase from Bacillus licheniformis PWD-1 and a recombinant B. subtilis FDB-29". Journal of Industrial Microbiology and Biotechnology. vol. 22, no. 6, pp. 608-616.

Williams, C. M., Richter, C. S., Mackenzie, J. R. and Jason, C. H. (1990). Isolation, identification and characterization of feather degrading bacterium. Applied Env. Microbiol.1:1509-1515.

Yamamura, S., Ramachandra, S. and Yokoyama, K. (2002). Characterization of a New Keratin Degrading Isolated from Deer Fur Bacterium. J. Biosci. Bioeng. 93, 595-600. 